Rosenbaum, H., \& Shachaf, P. (2010). A structuration approach to online communities of practice: The case of Q\&A communities. Journal of the American Society of Information Science and Technology, 61(9), 1933-1944.

\title{
A Structuration Approach to Online Communities of Practice: The Case of Q\&A Communities
}

\section{Howard Rosenbaum}

Indiana University Bloomington, 1320 E $10^{\text {th }}$ St. LI 001, Bloomington, IN.

E-mail: hrosenba@indiana.edu

\section{Pnina Shachaf}

Indiana University Bloomington, 1320 E $10^{\text {th }}$ St. LI 005A, Bloomington, IN. E-mail: shachaf@indiana.edu

This article describes an approach based on structuration theory (Giddens, 1979, 1984; Orlikowski, 1992, 2000) and communities of practice (Wenger, 1998) that can be used to guide investigation into the dynamics of online question and answer (Q\&A) communities. This approach is useful because most research on Q\&A sites has focused attention on information retrieval, information seeking behavior, and information intermediation and has assumed uncritically that the online $Q \& A$ community plays an important role in these domains of study. Assuming instead that research on online communities should take into account social, technical, and contextual factors (Kling, Rosenbaum, \& Sawyer, 2005), the utility of this approach is demonstrated with an analysis of three online $Q \& A$ communities seen as communities of practice. This article makes a theoretical contribution to the study of online Q\&A communities and, more generally, to the domain of social reference.

\section{Introduction}

Online communities have become routine and taken-for granted fixtures of the Web 2.0 environment. Some develop organically while others are created intentionally 
for a variety of reasons. Some are for entertainment, some for education, some are for business and taken as a whole, these communities are very popular. One type of online community that has been attracting increasing numbers of participants is the question and answer (Q\&A) site, where people are asking questions and providing answers (e.g., Yahoo! Answers, WikiAnswers, and Answerbag). Over the last 2 years, the number of visits to the top five Q\&A sites has increased by $889 \%$ and, for example, Yahoo! Answers has become the second most popular Internet reference site after Wikipedia (Alexa, 2010). These online Q\&A communities have attracted the attention of researchers who have focused primarily on information retrieval (e.g., Agichtein, Castillo, Donato, Gionides, \& Mishne, 2008; Bian, Liu, Agichtein, \& Zha, 2008) and information-seeking behavior (Gazan, 2006; Kim \& Oh, 2009; Oh, Oh, \& Shah, 2008). A few have studied information intermediation and examined answer quality (Harper et al., 2008; Shachaf, 2009). In spite of the frequent use of the term community in these studies, Q\&A sites have rarely been examined as online communities. This lacuna is surprising given the fact that researchers seem to assume uncritically that the online Q\&A community plays an important role, influencing their respective domains of study (Shachaf, 2010). However, what this role may be remains largely unexamined. Thus, analysis of Q\&A sites at the community level is useful and needed.

In this article, we argue that an approach based on structuration theory (Giddens, 1979, 1984) emphasizing the duality of technology (Orlikowski, 1992, 2000) and Wenger's (1998) concept of communities of practice can be used as a framework to guide investigation into the dynamics of online Q\&A communities. This approach is apposite because it focuses research attention on the social, technological, and contextual factors that contribute to the trajectories and dynamics of these communities. It also adds theoretical depth and richness to sociotechnical approaches to studying online communities.

We first provide background on online Q\&A sites and then briefly describe the concept of online communities, focusing attention on the concept of the online community of practice. Then, the structuration approach is explained, and its utility is illustrated with three Web-based question and answer communities (Answerbag, Yahoo! Answers, and the Wikipedia Reference Desk).

\section{Online Q\&A Sites}

Online Q\&A sites are "Web sites, where members can post questions, answer other members' questions, and rate other members' answers to their questions-all for free" (Roush, 2006, para. 2). Visitors to these sites are increasingly seeking answers to a wide variety of questions that are organized under topical categories; typically their questions and answers are archived and searchable. Under the assumption that everyone knows something (Roush, 2009), people answer the questions. On some of these sites, participants can rank the quality of answers and questions, and participants' reputations can be estimated, based on their past contributions (for example, see Answerbag, Yahoo! Answers). This can enhance members' motivations to increase their levels of participation on the site (Raban \& Harper, 2008). In fact, 
almost half of the visitors to these sites are returning participants (Hitwise, 2008).

Answer quality has attracted the attention of researchers who seek to distinguish higher from lower quality answers so that the former can be easily retrieved from a database of previously answered questions (e.g., Adami, Zhang, Bakshy, \& Ackerman, 2008; Agichtein et al., 2008; Bian et al., 2008;

Dom \& Paranjpe, 2008). Answer quality varies at the transaction level, and different sites provide answers to questions at different quality levels (Harper et al., 2008; O'Neill, 2007; Roush, 2006). This line of research is driven primarily by questions and theories within the domain of information retrieval (Shah, Oh, \& Oh, 2008).

One way scholars identify the quality of answers is based on the participant's reputation. Those who are likely to post high-quality answers can be identified through their past contributions, link analysis, and their activity distribution across subject areas (e.g., Chen, Zeny, \& Wenyin, 2006; Dom \& Paranjpe, 2008; Jurcyzk \& Agichtein, 2007). Others claim that good answers include references to external resources (Gazan, 2006), have greater numbers of links (Harper et al., 2008), are longer (Adamic et al., 2008; Harper et al., 2008), and are more accurate, complete and verifiable (Shachaf, 2009).

Some researchers have analyzed questions in the domain of information-seeking behaviors (Gazan, 2006; Kim \& Oh, 2009; Oh, Oh, \& Shah, 2008; Shah et al., 2008) and social reference (Shachaf, 2010). Shachaf and Rosenbaum (2009) proposed a sociotechnical interaction network research agenda for Q\&A sites, and others have integrated ideas from social informatics and online communities into their works under one of these other research domains (Adamic et al., 2008; Gazan, 2007; Shachaf, 2010). Still, a better understanding of Q\&A sites as online communities is needed, because these communities provide the context within which other information behaviors occur (Shachaf, 2010). Specifically, an understanding of the interactions among members of these communities, the ways in which they interact with the technology they use, and the dynamic interplay between structure and agency in these online social worlds could be informative and could enrich research in these other domains. For example, Shachaf (2010, p. 67) claims that a virtual community's "culture and norms, membership, technological infrastructure, and shared practices are critical contextual variables' for social reference research.

\section{Q\&A Sites as Online Communities}

Researchers have assumed that Q\&A sites are online communities and have treated them as such (e.g., Adamic, et al., 2008; Dom \& Paranjpe, 2008; Gazan, 2006, 2007). For example, Adamic et al. view Yahoo! Answers as an online community and Rafaeli and Ariel (2008, p. 257) argue that "Wikipedia defined itself as a community, and special spaces in Wikipedia are dedicated for communal activities. The rhetoric of community is to be found everywhere." They discuss the sense of community in Wikipedia based on research about online groups. Likewise, Gazan $(2006,2007)$ uses the term community when discussing Answerbag following the rhetoric of the site itself: "Answerbag is a community of people helping others" (Answerbag, 2009a, 
para. 1). Our treatment of these Q\&A sites is in alignment with these earlier works, where all of the members of each Q\&A site constitute its online community, and with the idea that "online communities can involve large groups" (De Souza \& Preece, 2004, p. 582).

At first glance, the concept of "online community" seems clear; it is made up of people who gather together and interact regularly in some type of digital space. However, according to Preece and Maloney-Krichmar (2003, p. 596) "there is no accepted definition of online community. The term means different things to different people." They review some of the more common definitions in several social science literatures and settle on one, which will be used here; an online community is a:

Social activity that involves groups of people interacting online. Such communities may be long or short term, large or small, national or international, and completely or only partially virtual. (Preece \& MaloneyKrichmar, 2003, p. 599)

However, there is more complexity to online communities than is indicated in this definition, so de Moor's (2006, p. 1) insights will also be taken into account; in addition to patterns of online interaction, online communities:

Build up a collective history of information created, discussions conducted, tasks performed, and goals accomplished. Especially in virtual communities, traces of these activities can be found in the many technologies used, like mailing list archives, web pages, and document repositories.

Recently, new frameworks have been proposed to refine the definition of an online community (e.g., De Souza \& Preece, 2004; Oh \& Lee, 2005). Oh and Lee (p. 1), in an effort to identify the key factors that comprise online communities, suggest that "member, interaction, shared goals and relationships [are] main attributes of online communities," and propose a framework for analyzing them. De Souza and Preece focus in their framework on the computer-mediated communication taking place among community members and outline a research agenda for online communities. In their framework, they explain that there are four attributes of online communities: policies, purposes, people, and software; these attributes are grouped under two concepts, sociability and usability.

Despite the contested nature of the concept (Preece \& Maloney-Krichmar, 2003), there is agreement that people in online communities are engaging in persistent conversations and interactions in online information spaces. There is also agreement that information and communication technologies (ICTs) play important roles in these communities.

As online communities proliferate in the Web 2.0 environment, researchers are asking how such communities are formed, sustained, changed over time, and dissolved and are using a variety of theoretical and methodological tools to study them, seeking to understand their trajectories and dynamics. One feature common to these communities is that they are digitally mediated and persistent settings 
within which people routinely interact, constituting and reconstituting their social worlds over time. They have collective histories and as participants interact in them, norms and guidelines develop that shape the behaviors and interactions of participants. Another feature common to all online communities is a reliance on sophisticated technical infrastructures both as sites for interaction and as means of access for participants.

It is possible to study these online communities in two separate streams of work, one examining their social patterns and characteristics and the other investigating the impacts of the technical components involved. However, from the standpoint of social informatics, research that seeks to understand the dynamics of online communities theoretically and empirically must take into account both social and technical factors and their complex interplay (Kling et al., 2005). As will be argued below, one approach that may be useful for understanding this interplay between the social and the technical is Giddens' structuration theory $(1979,1984)$, because it combines these streams into a coherent and integrated approach. Particularly as modified by Orlikowski's $(1992,2000)$ concept of the "duality of technology," and with the addition of Wenger's (1998) concept of "communities of practice," this approach provides a systematic, sociotechnically-oriented framework that can be effectively used to study online communities. This is a useful approach because it accounts for the technological and social systems that constitute these communities and the intertwined interactions that are made possible by the routine use of ICTs.

\section{A Structuration Approach to Q\&A Sites}

Giddens' (1979; 1984) structuration theory can be the basis of a constructive approach to bring to the study of online Q\&A communities because it can illuminate the complex interrelationships among people, the ICTs they design and use, the social practices supported by these ICTs (of which work practices are a subset), and the organizational and socialcontexts in which they use them. This theory has been used in a variety of disciplines including sociology, political science, management, education, and, more relevant to this paper, information science and systems (Jones \& Karsten, 2008). Many researchers have adopted versions of structuration theory in the information disciplines and it has "been used extensively in IS (information systems) to help reveal how technical systems can support or hinder human interaction in societal, organizational, and personal contexts" (Evans \& Brooks 2005, p. 215).

Giddens' theory is quite complex and a full and detailed treatment is well beyond the scope of this article (for a clear and critical analysis of structuration theory, see Stones, 2005). Although researchers in diverse fields have made use of structuration theory in their empirical work, its importation should be approached carefully. Giddens (1991, p. 213) comments:

On the whole I like least those works in which authors have attempted to import structuration theory in toto into their given area of study... . In many more 
confined areas of empirical research it is not especially helpful to drag in a large apparatus of abstract concepts. I like most those usages in which concepts, either from the logical framework of structuration theory or other aspects of my writings, are used in a sparing and critical fashion.

Taking note of this caution, three key concepts relevant to the study of online communities - structuration, the duality of structure, and social practices-will be discussed below and used to develop a structurationally-informed concept of communities of practice, which will then be used in the context of online Q\&A sites. These three structurational concepts are useful here because they are at the core of the theory and can account for the dynamism of online communities; they are taken together because they are deeply enmeshed in each other and, as will be seen below, analytically complement each other.

The term "structuration" refers to the ongoing, persistent and routine moments during which society and the individual are created and recreated during interaction. Both structure and individuals' social identities emerge as largely unintended consequences of the structuration process. What makes structuration, and, therefore, social life, possible is the instantiation of structure as it is enacted in social practices. This is because:

The essential recursiveness of social life is constituted in social practices; structure is both medium and outcome of practices. Structure enters simultaneously into the constitution of the agent and social practices, and "exists" in the generating moments of this constitution. (Giddens, 1979, p. 5)

This is the "duality of structure;" it is a central concept in the approach because it asserts that human agency (as actions and interactions in the form of social practices) can only take place through and because of structure and is enabled and constrained by the structures within which people act. As people draw upon these structures to give shape and form to their interactions, they simultaneously recreate (and sometimes change) these structures. The two sides of the duality are that structure makes social practices possible and is simultaneously reproduced by these practices. This is what is meant by the Giddens' $(1979$, p. 5) claim that "structure is both medium and outcome of practices." Structures, in Giddens' view, comprise sets of rules and resources that are only instantiated in recurrent social practices (Orlikowski, 2000). The focus on social practices is critical because, as Giddens (1989, p. 252) states, the "starting point for theoretical thinking and empirical work in the social sciences should ... be understood as the analysis of recurrent social practices." Technology, in this view is a resource that is drawn upon as people engage in social practices. Orlikowski's (1992, p. 423) insight that there is a corresponding "duality of technology" represents an important step in bringing structuration into information systems (and information science) research because it is a " $t \mathrm{t}]$ heoretical conceptualization of technology, which underscores its sociohistorical context, and its dual nature as objective reality and as socially constructed product." The duality of technology offers an alternative view to tool-based or technologically deterministic views because it assumes that ICTs are structural 
resources that can enable and constrain human action in different ways.

In this way, technology as an artifact is subsumed into the conception of structure with its dual nature preserved allowing it to play an important role in the structuration of social life, and, in the context of the argument presented here, in the structuration of the social dynamics of online Q\&A communities. Orlikowski (2000, p. 407) explains that in modern organizations, technology has a central role in the creation and recreation of social life and in shaping the relationship between agency and structure:

Structures of technology use are constituted recursively as humans regularly interact with certain properties of a technology and thus shape the set of rules and resources that serve to shape their interaction.

Here, in contrast, the structures of technology use are enacted outside of the confines of the organization. Participants in online Q\&A communities routinely make use of ICTs as they act and interact with each other. The duality of technology implies that as people use various ICTs, for example, blogs, wikis and other Web 2.0 technologies, they are creating and recreating themselves and their communities in ongoing moments of structuration. They are developing, maintaining, and sometimes changing the rules and the resources that become the structural media through which they interact with each other and the sources of enablement and constraint over time. Researchers have begun to notice how ICT use in online communities affects both identity formation and management (Farquhar, 2007; Lamb \& Davidson, 2005), and the organization of the community (Evans \& Brooks, 2005). For example, Lamb and Davidson argue that in an online community of scientific researchers, the use of ICTs to support collaboration has at least an indirect impact on participants' management of their scientific identities. Farquhar also finds that participants in an online fantasy sports community reproduced some features of their offline worlds online but there were also important differences in roles, rules, and types of communication attributable to the online environment. Evans and Brooks (2005, p. 215) consider the general case of people working together in online communities and argue that the use of structuration theory can lead to a "greater understanding of the underlying structures that emerge from collaboration using new technology."

These three key concepts from structuration theory (structuration, the duality of structure, and social practices) can be used to analyze Q\&A online communities. The process of structuration can help to explain the fundamental dynamism of these communities by sensitizing researchers to the ways in which these communities are created, recreated, and changed as people engage in social practices within them, drawing upon the rules and resources of the community's structure. The main social practices include such interactions as asking and answering questions, evaluating answers and users and engaging in meta-conversations about the community and its norms and rules. These are examples of the routine social practices through which the community is sustained and the duality of structure is enacted. The rules and resources of these communities enable and constrain the actions and interactions of participants whose social practices reconstitute the community's 
structure. ICTs are structural resources and as such, have a fundamental duality that allows them to influence and shape the social practices of the participants using them while being influenced by this use. Out of the duality of technology comes the shape of the community and the identities of those participating in it.

Among the outcomes of routine interactions in online communities are the creation and recreation of structures that enable and constrain social interaction and practices within the community. This is one side of the duality of technology; people's actions and interactions reinforce and can sometimes change the ICTs they use. On the other side of the duality of technology, participants, as they use ICTs, are enacting social practices through which they develop, maintain and change their identities in the community. Among certain types of communities, the emergence and routinization of social practices and occurrences of identity formation can lead to the emergence of communities of practice (Baker-Eveleth, Sarker, \& Eveleth, 2005; Wenger, 1998).

\section{Structuration and Communities of Practice}

By integrating the concept of "community of practice" (CoP) into the structuration approach described above, the analytic reach of the approach can be extended and its empirical value enhanced. This is important because one of the limitations of Giddens' theory is its lack of discussion of its empirical applications in the social world. We discuss next the concept of CoP, describe three points of contact between structuration theory and CoP that allow their integration, argue that online Q\&A sites are CoPs and ground this contention with three examples of Q\&A sites.

Lave and Wenger (1991) introduced the concept of the community of practice into the literature as part of a discussion of how informal learning takes place in organizations. They (p. 98) describe a CoP as "an intrinsic condition for the existence of knowledge, not least because it provides the interpretive support necessary for making sense of its heritage." Arguing for the fundamental nature of CoP, Lave and Wenger (p. 29) claim "learners inevitably participate in communities of practitioners" in ways that allow them to develop "mastery of knowledge and skill" as they "move towards full participation in the sociocultural practices of the community." Newcomers establish relations with experienced members of the CoP through which they engage in situated learning about the "activities, identities, artifacts ... knowledge and practice" (Lave \& Wegner, p. 29). A more recent definition emphasizes the social nature of CoPs as "groups of people who share a concern, a set of problems, or a passion about a topic, and who deepen their knowledge and expertise in this area by interacting on an ongoing basis." (Wenger, McDermott, \& Snyder, 2002, p. 4). Tompsett and Alsop (2003, p. 62) emphasize that a community of practice "requires mutual engagement, shared repertoire and a common enterprise." The concept of CoP has been adopted widely and has undergone an evolution (for a comprehensive and critical review of the concept and its change over time, see Hara, 2009). As the Internet has become an integral part of learning and social life, interest in online communities of practice has developed among researchers and practitioners (Murillo, 2008). 
There are three significant points of contact between communities of practice and structuration theory that facilitate their integration: (a) the central role of social practices, (b) the importance of a fundamental duality (of participation and reification) through which the processes and structure of the community are maintained and changed over time, and (c) the extent to which identity is a critical outcome of the interactions among participants in the community. Warren (2004, p. 27) has noticed this overlap, claiming that Lave and Wegner's (1991) treatment of the concept of $\mathrm{CoP}$ "draws on Giddens to some extent (as well as a wide range of other theorists)." In fact, Wenger (1998, p. 23) places his work within the domain of structuration in a footnote, explaining "Though my purpose is not to address directly the theoretical issue of the structure-action controversy, I will work within assumptions similar to Giddens."

First, ongoing and routine practices are at the core of a CoP and, according to Wenger (1998, p. 47), the concept of practice connotes doing, but not just doing in and of itself. It is doing in a historical and social context that gives structure and meaning to what we do. In this sense, practice is always social practice.

In a CoP, practices are enacted within a context that includes structures and meanings that are created, maintained and sometimes changed by the community's participants (Baker-Eveleth et al., 2005). Wenger (1999) describes this process as reification, or "the process of giving form to our experience by producing objects that congeal this experience into 'thingness"' (p. 58) and argues that reification "is central to every practice" (p. 59). Engagement in practices also involves participation, which Wenger (pp. 55-56) sees as "both action and connection" with "the possibility of mutual recognition ... [w] hat we recognize has to do with our mutual ability to negotiate meaning."

Haythornthwaite and Hagar (2005, pp. 314-315) note the importance of social practices in the shaping of participants' uses of ICTs, an important structural resource, and in the emergence and persistence of structural rules; this is particularly the case in an online CoP, where the "way social technologies ... are used arises from group practices, including norms about what is discussed and the languages and genres considered appropriate for communication". Moreover, these practices are not static; they emerge and evolve in and through participation and reification and "constitute and reconstitute" (Orlikowski, 2002, p. 270) the norms, conventions, and knowledge that become parts of the structure of the CoP. Social practices are, therefore, the first point of contact between structuration theory and CoP, playing a central role in both.

The second point of contact involves a fundamental duality of participation and reification through which the processes and structure of the community are maintained and changed over time; this duality echoes the duality found in structuration. According to Wenger (1998, p. 65),

This duality is a fundamental aspect of the constitution of communities of practice, of their evolution over time, of the relations among practices, of the identities of participants and of the broader organizations in which communities of practice exist. 
More specifically, Wenger (1998, p. 56) notes that "participation in social communities shapes our experience, and it also shapes those communities, the transformative potential goes both ways." Reification also has a dual nature and (Wenger, 1998, pp. 59-60) "shapes our experience ... [and] ... can do so in very concrete ways," referring "to both a process and its product." As participants interact with each other and engage in informal situated teaching and learning in a $\mathrm{CoP}$, the process of structuration is unfolding; the "key point to remember about the co-constitution of agents and structures ... is that it occurs in and through practice. CoPs, therefore, play a crucial role in the mutual construction of agents and structures" (Adler, 2005, p. 12).

The duality of structure is therefore an essential component in the life of a CoP and can account for its dynamism in terms of stability and change. The structure of the CoP comprises rules and resources that are instantiated as participants enact routine social practices and "emerges from the engagement of members" (Baker-Eveleth et al., 2005, p. 8). In this sense, the stability of a CoP exists because of the "reproduced relations between actors or collectivities, organized as regular social practices" (Berends, Boersma, \&Weggman, 2003, p. 1039). Dougherty (2008, p. 423) reinforces this insight, observing that "people work naturally in communities of practice if they have 'seeding structures' such as rules, symbols, and perspectives that act as focal points around which they can identify and interact... ." One particular resource, knowledge, is deeply implicated in changing CoPs. Østerlund and Carlile (2003, p. 16) find that "in the everyday unfolding of practice.. . new structures continuously emerge, such as socially distributed repositories of knowledge." The potential for change is an attribute of the background knowledge that constitutes CoPs and their specific practices. As the background knowledge on which individuals draw changes, they modify their understandings of their realities and discourses and thus may be able to participate in new practices. CoPs, thereby, help create, diffuse, select, and institutionalize knowledge that becomes the background of new practices (Adler, 2005).

A third point of contact between structuration and CoPs includes the processes of identity formation and maintenance. At the core of CoP are processes of identity formation and maintenance that provide the "glue" that holds these communities together (Hara, 2009). These processes are also important in structuration theory, which holds that a largely unintended outcome of the structuration of social life is the development of individuals' identities. Warren (2004, p. 27) sees a link between structuration and CoPs because the "development of a practice requires the negotiation of identity through engaging with and being acknowledged by a set of actors in a particular area of activity." According to Østerlund and Carlile (2003), as participants interact within the community and carry out the social practices that characterize the community, they are negotiating and renegotiating their identities.

Taken together, these points of contact indicate that an integration of $\mathrm{CoP}$ into structuration theory can provide a framework for empirical analysis of Q\&A sites. However, before such an analysis can be conducted, the question of whether these sites are online CoPs is addressed. The utility of this approach depends on the ability to identify Q\&A sites as CoPs, rather than assuming that they are. 


\section{Q\&A Sites as Online Communities of Practice}

Here, we argue that Q\&A sites display the characteristics of a specific type of community, an online $\mathrm{CoP}$; the practice of answering questions is the common social practice for the members of these communities. This activity drives the use, formation, design and implementation, and maintenance of CoPs. Q\&A sites are virtual CoPs (Wenger, 1998), as can be seen an examination of three sites in light of two key features of CoPs that are drawn from Wenger's seminal work, his later discussion of the possible impacts of technology on communities of practice (Wenger, 2001), a recent framework of virtual communities of practice (Murillo, 2008), as well as prior efforts to identify online communities of practices (Hara, \& Hew, 2006; Hara, Shachaf, \& Stoerger, 2009).

To illustrate how Q\&A sites are, in fact, CoPs, three Q\&A sites have been chosen (see Table 1),Yahoo! Answers, Answerbag, and the Wikipedia Reference Desk because our observations can be enhanced by prior research (Adamic et al., 2008; Gazan, 2006, 2007; Shachaf, 2009). Yahoo! Answers is the most popular Q\&A site, Answerbag is the first Q\&A site to provide social reference services, and the Wikipedia Reference Desk operates within the Wikipedia community. We seek to make the case below that all three communities are engaged in the social practice of question answering, and that they comprise communities of practice. The structuration approach is intertwined in this identification process and is integrated into the discussion of each of the following sections.

TABLE 1. The three Q\&A sites and their URLs.

Q\&A site URLs

Answerbag

Wikipedia Reference Desk

Yahoo! Answers http://www.answerbag.com/

http://en.wikipedia.org/wiki/Wikipedia:RD

http://answers.yahoo.com/

Wenger (1998) identifies two key criteria of communities of practice: (a) practice-as meaning, as community, as learning, as boundary, and as locality; and 2) identity in practice-as identities in participation and nonparticipation, modes of belonging, identification, and negotiation. Later, he describes 14 community principles that are affected by technological factors (Wenger, 2001). Murillo (2008) builds on Wenger's work and emphasizes two types of traits in the context of virtual CoPs: essential and exemplary. The essential traits are based on Wenger (1998) and include: mutual engagement, joint enterprise, shared repertoire, community, learning and identity acquisition. The exemplary traits include high-quality institutional documents, a focus on a profession, highly focused discussions, a coreperiphery interaction structure, a high volume of online interaction, a low level of conflict, and a mid-sized online group. Murrillo (2008) maintains that the presence of essential traits is considered conclusive evidence of an online CoP, but the second 
set of traits makes an online CoP more focused, productive and energetic. Murillo (2008, para. 14) argues "[t]hese attributes cannot by themselves single out a community of practice, because they can be present in all kinds of virtual communities." At the core are the two main CoP characteristics that Wenger (1998) originally identified, identity and practice. Thus, the following analysis focuses on these two core dimensions.

Practice. Practice is the first key characteristic of a CoP (Wenger, 1998). This is manifested through the community (Murillo, 2008;Wenger) as: (a) mutual engagement, (b) joint enterprise, and (c) shared repertoire. These dimensions of practice are discussed and illustrated with examples drawn from the three Q\&A sites. Together, they illustrate how members of Q\&A sites are deeply involved in social practices that help them define their communities, the importance of which, as Wenger (p. 56) points out, is that "participation in social communities shapes our experience, and it also shapes those communities, the transformative potential goes both ways." Because social practice is one of the three points of contact between CoP and structuration the next sections are instrumental for our argument.

Mutual engagement of participants. Mutual engagement is manifested through collaborative problem solving, a high volume of participant interaction, and a core-periphery structure. Participant interaction and collaborative problem solving are social practices that are involved in forming and maintaining identities. Participants in Q\&A sites are engaged in collaborative problem-solving activity while answering questions and evaluating questions and answers; this is one of the cornerstones of mutual engagement. Gazan (2007) finds that "answering and rating questions is a shared responsibility" of the community. The collaborative process is documented online and becomes an integral part of the digital archive of questions and answers. This archive then serves to support mutual engagement among participants. In structurational terms, this digital archive becomes a structural resource that can be invoked and drawn upon during participation in the social practice of question answering. Community members can relate to documents and processes from their past shared experiences and these documents then become instrumental in forming their shared repertoire (Wenger, 1998). These experiences facilitate the creation and maintenance of the community routines and structure. The mutual engagement of participants is both partial and complementary (Wenger, 1998); community members do not have complete and homogenous knowledge, and they can rely on the complimentary knowledge of other members of the community.

Besides "collaborative problem solving" online mutual engagement also involves "a high-volume of participant interaction ... and a core-periphery structure, reflecting the potential for various degrees of engagement, which enables the active participation of people other than core members" (Murillo, 2008, para. 17). Any interested person can participate and answer questions on each of these three Q\&A sites and "being included in what matters is a requirement for being engaged" (Wenger, 1998, p. 74). The level of participation, however, in asking 
(Gazan, 2007) and in responding varies (Adamic et al., 2008; Shachaf, 2009). A limited number of participants on each Q\&A site forms the core of the community of practice; they are responsible mostly for answering questions (Adamic et al., 2008; Shachaf, 2009). On Q\&A sites, many active users contribute answers in specific subject domains and only a few are boundary spanners, working across subject domains. On Yahoo! Answers, members who are active on specific topics provide better answers than those who participate on multiple categories (Adamic et al., 2008). Various levels of engagement among those who ask questions exist as well. For example, on Answerbag there is a distinction "between questions submitted by 'Seekers' - those who interact with the community about their question - and ... 'Sloths,' who post their question ... and interact no further"' (Gazan, 2007, p. 244).

Negotiation of a joint enterprise. Negotiation toward a shared understanding of the nature and purposes of the community's activities is another important aspect of a community of practice. It is a social practice that creates and recreates the structure of the community over time; Adler (2005, p. 12) sees this as the structuration of a CoP because "the co-constitution of agents and structures ... occurs in and through practice." Each of the three Q\&A sites enables and facilitates this negotiation process, fostering community interaction. The negotiation process varies tremendously from one Q\&A site to another, from a pure bottom up approach in Wikipedia, to a top down approach in Yahoo! Answers. Negotiation of the site's standards and policies is a manifestation of this process in Q\&A sites. At the Wikipedia Reference Desk the community creates a set of guidelines for asking and answering questions; these guidelines are routinely being negotiated and modified by Wikipedia participants. The guidelines specify the goal of the reference desk, what it is and what it is not, what is on-topic and off-topic, as well as how to answer questions (Wikipedia, Guidelines, 2009). Unlike the bottom-up approach to the site's policies and guidelines on the Wikipedia Reference Desk, negotiation processes on Yahoo! Answers are more of a top-down process. Still, negotiation of the joint enterprise occurs as part of the practice on the Yahoo! Answers Suggestion Board, where community members communicate with each other. Yahoo!Answers' participants also use the Answerholics Anonymous Yahoo group, and Yahoo! Answers on Facebook to communicate with each other. Likewise, on Answerbag, users are engaged in negotiation of the joint enterprise at the Answerbag category and all of its subcategories. "Participants translate their knowledge, experience and opinions into content that both adheres to and continuously redefines the standards of the community" (Gazan, 2006, p. 73).

According to Wenger (1998, p. 80):

The enterprise is never fully determined by ... a prescription ... the power .. . that institutions, prescriptions, or individuals have over the practice of the community is always mediated by the community's production of its practice.

Negotiating a joint enterprise, in turn, increases the mutual accountability among community members (Wenger, 1998). Mutual accountability to the enterprise includes not only answering questions on the Q\&A site, but also 
Being responsible to others by not making their lives more difficult... (it) is something they enforce among themselves ... because they all understand that ... (it) is part of their joint enterprise ... that is sometimes violated. (Wenger, 1998, p. 81)

The fight against trolls (Answerbag, 2009b), reporting abuse on Yahoo! Answers as part of the community moderation, or the efforts to fight vandalism on Wikipedia, are manifestations of an online community's efforts to maintain and negotiate mutual accountability. These are different ways in which the regular social interactions and engagement in social practices on Q\&A sites can be seen as examples of the structuration of these sites through which their structures and the identities of participants are negotiated, maintained, and sometimes changed.

Shared repertoire. Guidelines and symbols that are shared by the Q\&A community form its shared repertoire, which is the "third characteristic of practice as a source of community coherence" (Wenger, 1998, p. 82). From a structurational perspective, this repertoire is a resource that is part of the CoP's structure that is characterized by "its availability for further engagement in practice" (Wenger, 1998, p. 83). The community "will gradually develop a shared online repertoire, i.e., easily accessible tools, routines, knowledge repositories and other instrumental aids to engagement" (Murillo, 2008, para. 18). This repertoire includes routines and ways of doing things, in addition to stories and symbols (Wenger, 1998). Each of the three online communities maintains publicly available guidelines, an archive of questions and answers, and a short description about the sites to "tell visitors what the community is about, or a FAQ to avoid needless repetition of routine questions" (Murillo, 2008, para. 18). These not only reflect past negotiation and mutual engagement, but are also used for further negotiation of meaning in practice.

The use of symbols on the three Q\&A sites becomes a crucial component of the community's shared repertoire; still, the symbols vary among sites. For example, on Yahoo! Answer, and on Answerbag, participants pick avatars to represent them visually, while on the Wikipedia Reference Desk, Wikipedia user names represent participants. On Yahoo! Answers and Answerbag, community members' reputations are presented on their pages in addition to personal information that they can add. Member reputation is determined by a set of criteria that is unique to each of these two sites and systematically calculated and shared. Likewise, some active participants on the Wikipedia Reference Desk indicate their Wikipedia status (e.g., bureaucrat) on their pages. However, the Wikipedia Reference Desk is different from the other two in that member reputation is not systematically presented on the member page and participants are empowered to decide whether information about their contributions is posted on their member pages. Not only do the reputation symbols vary among the three communities, but the meanings of these symbols also vary. Furthermore, on Yahoo Answers and Answerbag, reputation is determined by participants' contributions and behaviors on the Q\&A site alone, but on Wikipedia, however, reputation is based on contribution to the Wikipedia project in general but not specifically to the Wikipedia Reference Desk. 
Although these symbols vary and the repertoire of each site differs from other sites, the role of these symbols, routines, and guidelines is similar and serves as an instrumental feature in the community's social practices and user interactions.

Identity. The second key characteristic of a community of practice is identity (Wenger, 1998), as manifested through: (a) identity in practice through participation and nonparticipation and (b) modes of belonging. Examples of how each of the three Q\&A sites display these two dimensions of identity are provided here. Identity is key also to structuration, as an outcome of routine social practices and the process of structuration.

Identity in practice through participation and nonparticipation. Wenger (1998, p. 153) argues that the dimensions of practice become dimensions of identity because "[m]embership in a community of practice translates into an identity as a form of competence. An identity ... is relating to the world as a particular mix of the familiar and the foreign ...." On Q\&A sites people who are members of the community and participate in posting and answering questions become familiar with the meaning of the enterprise and with the shared repertoire of the community; it is through these experiences and by knowing what is familiar to them that they know who they are. This identity, according to Wenger, is temporal and continuously being negotiated. In this sense, identity formation in a CoP occurs in much the same way as in structuration, where identity is an outcome of people's mutual engagement in social practices during which they draw upon structural rules and resources, or, in Wenger's (1998) terms, shared repertoires.

It is through the practice in which one is engaged as well as the practice in which one is not engaged that identity is formed. For example, being familiar with the ways of doing things on one Q\&A site and not on another site is a mechanism to strengthen identity. On the various Q\&A sites, members of the CoPare familiar with and engaged in local practices and shared repertoire; but, at the same time many of them chose not to be engaged with the other Q\&A sites. For example, on Answerbag, a question was posted to the community: "Which is better, Answerbag or Yahoo Answers?" Everyone who posted a response or a comment agreed that Answerbag is better. Participation in this discussion included Answerbag members, those who identified with the Answerbag community of practice but not with the Yahoo!Answers community of practice. Furthermore, community members, in support of their choice of Answerbag over Yahoo! Answers, repeatedly justified their preference by arguing that Answerbag is a better community. This reflects a sense of belonging and identification that is shared among the responders. A few responders commented that they either had a Yahoo! Answers user name but did not like to use it or were Yahoo! Answers "refugees." Similar questions were posted on Yahoo! Answers, where all the responses were in favor of Yahoo! Answers; there, however, many answered that they were not at all familiar with Answerbag. A person chooses to actively participate in a Q\&A community of practice, and by participation, becomes identified with this community; at the same time, by not participating in another community, a person strengthens his or her identity as a 
member of the community.

Modes of belonging. There are three distinct forms of belonging that help make sense of the processes of identity formation and learning (Wenger, 1998): engagement, imagination, and alignment. Engagement reflects people's active involvement in a community of practice. Belonging through imagination (creating images) occurs during the course of seeing connections through experiences. Choosing where to invest energy is the process of forming identity through alignment; it is to coordinate one's activity with those of other members of the community. People, through active participation (engagement), form their sense of belonging to the Q\&A sites. The longer they are active on the site, and the more questions and answers they post, the more they identify with the community. The process of forming identity by belonging through engagement varies among the three sites. On Yahoo!Answers, member pages include the number of answers, questions, and points that each person has gained over time, as well as the percent of their best answers and the member's level. Likewise, an indication of community participation is presented on each Answerbag member's page. An Answerbag member page includes the number of questions, answers, and moderations in which the person has been involved, as well as the points and rank of the person within the Answerbag community. Unlike these two Q\&A sites, on the Wikipedia Reference Desk, the individual designs her own user page, which often does not include an account of her participation history or the amount of their contributions to the Wikipedia Reference desk. Although participants on Yahoo! Answers and Answerbag form their identities within their Q\&A site community of practice, members of the Wikipedia Reference desk form their identities within the larger Wikipedia community; a community that is engaged in writing encyclopedia articles where answering questions is only a marginal activity.

\section{Discussion}

Prior treatment of the concept of online communities in research on Q\&A sites has been very simplistic. The community was assumed to exist and provide the context for the various studies Shachaf (2010). In information retrieval research, researchers rarely even review literature on online community and use the term "community" in a cursory manner to refer to the group of users who interact on these sites (one exception to this trend is the work of Adamic et al., 2008). Research in information intermediation or information-seeking behavior and use does not completely ignore social interactions, but when user behaviors are analyzed, the technological component is a merely contextual feature (e.g., Gazan, 2006; Harper et al., 2007; Oh, Oh, \& Shah, 2008; Shachaf, 2009, 2010). Shachaf and Rosenbaum (2009) call for research that will address this lacuna and suggest focusing on the sociotechnical interaction network (STIN), but they do not provide such an analysis. Here, we suggest and illustrate how a structuration approach to online CoP, using Q\&A sites as a representative case, can address this gap and unpack the black box of "community." We believe that research of online Q\&A sites can benefit through a better understanding of the interaction between the online CoP and the technology 
of these Q\&A sites.

Recent approaches to studying online communities (e.g., de Souze \& Preece, 2004; Oh \& Lee, 2005) suggest that there are useful analytic frameworks that could be utilized to unpack the concept of the online community of social Q\&A sites. Oh and Lee (2005) argue that online communities can be analyzed through the lens of a social or sociotechnical perspective (see Oh and Lee, 2005, for an extensive review), and that the sociotechnical perspective involves the sociability, usability and fit (de Souze \& Preece, 2004; Oh \& Lee, 2005). The structuration approach described here, however, focuses on the interrelationships among them. It is used for understanding the complex networks of people, ICTs, and their structured interrelationships, focusing on the online community as a CoP.

Using a structurational approach to study online Q\&A communities means that researchers are sensitized at the outset to the dynamic interplay between structure and agency in digitally mediated social worlds. This is sensible because online communities can be seen as ICT-based social networks within which heterogeneous components interact. Invoking the duality of structure researchers can attend to the sets of rules and resources that are relevant in these settings, seeking to understand the range of ways that people draw upon and enact these sets as they routinely interact and understand how people shape and are shaped by structural rules and resources. Invoking the duality of technology, a particularly significant structural resource in digital social spaces, researchers can look for instances in which people alter the ICTs they use and can attend to the ways in which ICT use shapes online interaction and the structure of online communities. They can also focus on the ways in which ICT use contributes to the persistence of online communities, enabling and constraining what people do in these communities.

There is much more sociotechnical complexity to many digital spaces, such as online Q\&A communities, than is often realized (Kling et al., 2005). Such complexity means that the ICTs that support online Q\&A communities and are used by participants are not isolated from the organizational and social contexts in which they are embedded. In fact, there is a strong bidirectional relationship between participation in online communities and the technologies on which participants and communities depend, similar to the bidirectionality described by Wenger (1998) who describes a mutual shaping and interdependence between participation in a CoP and, through reification, the community's structure. In this sense, the stucturation approach can provide insights into the mutual shaping between structure, seen here as technology, with its dual nature, and agency, seen here in the activities of participants, in the social context of the online community.

Structuration theory provides a framework for understanding complex networks of people, ICTs, organizations, and their structured interrelationships. It assumes that such a network can be best understood through the processes (rather than results) of social interactions among its heterogeneous components.

In the same way as other sociotechnical networks, online Q\&A systems are constituted out of heterogeneous components, which include people (participants including question posers, question answerers, question and answer evaluators, readers, system moderators, system technicians, advertisers, and others) nonhuman 
resources (technologies, funding, digital collections, status of the host organization), norms, and rules, the contexts of resources and of the parent organization (e.g., Yahoo for Yahoo! Answers, Answer.com for WikiAnswers, and Amazon for Askville), as well as the social, political, and economic relationships among these resources. From a structurational standpoint, the design, implementation, operation, maintenance, and use of Q\&A sites are affected by interactions among these heterogeneous components (Jackson, Poole, \& Kuhn, 2002).

\section{Conclusion}

This article has argued that by using a structurationally informed concept of communities of practice, our understanding of Q\&A sites as communities is enhanced. The first step was to establish that these sites are online communities. This was done by demonstrating that participants in Q\&A sites are groups of people who interact online in restricted digital spaces, although the boundaries of these spaces are porous. Engaging in persistent conversation mediated by technology, participants form relationships and create and share norms, guidelines, and other rules of behavior. They develop and maintain archived collective histories that contain traces of information created and exchanged, tasks performed, goals accomplished, and other artifacts of the community's interaction. As they participate in these communities, their routine interactions make use of the rules and resources that provide structure for the community; in doing so, participants constitute and reconstitute the community. Online communities, therefore, have histories, dynamics and trajectories, all of which can be described. These are the primary characteristics of the conception of online communities derived from Preece and Maloney-Krichmar (2003), De Souza and Preece, (2004), and de Moor (2006).

The second step was to articulate a structuration approach to understanding Q\&A sites and to do so in a way that laid the groundwork for integrating the concept of communities of practice into the framework. This was done by making use of three key concepts of structuration theory that are relevant to the concept of CoP and to the study of online Q\&A sites: structuration, the duality of structure, and social practices. These concepts come together in the following way: the ongoing and routine social practices that are central to the formation and maintenance of a $\mathrm{CoP}$ unfold through a process of structuration, where the structure of the online community and the participants' identities are co-constituted. In a CoP, social practices are a form of participation that plays a central role in the life of the community because it "shapes our experience, and it also shapes those communities, the transformative potential goes both ways" (Wenger, 1998, p. 56).

The rules, resources, meaning, symbols, and other features of CoP are structural elements that are routinely drawn upon by participants as they interact and, thereby, recreated through these interactions; this is the duality of structure. Structure is the medium through which participants interact and is an outcome of their interaction. Wenger (1998, p. 65) describes this duality as "fundamental" to "the constitution of communities of practice," and instrumental in shaping "the identities of participants." Negotiation of this structure is a routine social practice that has an outcome: a shared understanding of the nature and purposes of the community's activities. This social practice creates and recreates the structure of the 
community over time. Recalling that technology is a structural element, the duality of technology is, therefore, essential to the existence of an online CoP, making possible the processes of identity formation and maintenance that are central and vitally important to these communities. It implies that as people use various ICTs to interact on Q\&A sites, they are creating and recreating themselves and their communities in ongoing moments of structuration. They are developing, maintaining, and sometimes changing the rules and the resources that become the structural media through which they interact with each other and the sources of enablement and constraint over time.

The third step was to analyze Q\&A sites as online CoP. In doing so, some of the structurational elements that contribute to their dynamics were foregrounded in ways that increase understanding of the formation, maintenance, change, and sometimes dissolution of these communities. As people interact in these communities, primarily by engaging in the practices of questioning, evaluating, and answering, they routinely draw upon and make use of the rules and resources, particularly technology, that constitute the community's structure, or, in Wenger's (1998) terms, the shared repertoire. In doing so, they reinforce the social and work practices of the community, recreate the community's structure, and develop and strengthen their individual and collective identities. This can be seen as people negotiate their joint enterprise, the rules and guidelines of the community, and the community archive. Online communities of practice emerge because of the structuration process. The importance of structuration is clear in the context of Yahoo! Answers, Answerbag, and the Wikipedia Reference Desk.

As part of the fourth step we explained how and why a structuration approach to the study of Q\&A sites as online CoP is beneficial and much needed. We explained that to address the gap in the literature on Q\&A sites, and online communities, a sociotechnical approach that integrates structuration and CoPs to analyze and understand these communities is a useful way to proceed. In short, structuration can provide a theoretical grounding for the dynamism of CoP; Wenger (1998, p. 23) agrees in principle, explaining that "though my purpose is not to address directly the theoretical issue of the structure-action controversy, I will work within assumptions similar to Giddens." The concept of the duality of structure captures the relationship between participation, seen as social practices, and reification, seen as the process of structuration, and provides a clear sense of the ways in which it can account for the development of a shared repertoire, seen as rules and resources that constitute structure. When considering an online CoP, the duality of structure can be extended to include technology as a component of structure, so the social practices in which participants engage are mediated by technology, which is a resource used in practice, enabling and constraining the actions and interactions of participants in the community.

The approach described here has been used to make a theoretical contribution to the research discourse about online Q\&A sites and the larger domain of social reference. Relying on existing research, it was used to unpack the concept of online communities as an indication of its potential utility. We believe that it can be used to investigate complex features of Q\&A and other online communities. For 
example, by exploring the structurational features of different $Q \& A$ sites as online $\mathrm{CoP}$, an understanding of the differences among these sites, particularly focusing on their online participation and reification practices, may help explain why participants engage in some sites and not others. Assuming that participants in a Q\&A site regularly interact with certain properties of the site's technologies, it may be possible to describe and explain how their participation shapes the set of rules and resources that, in turn, shape their interactions on the site and their online communities. By focusing on how sites utilize different technological infrastructures and how participants invoke these and other structural resources, it may be possible to uncover the ways in which different Q\&A sites offer different types of rewards mechanisms and address different types of users. In turn, this work may inform designer, community moderators, and participants, as well as researchers of users artifacts (information retrieval) and behaviors (information seeking and use).

\section{Acknowledgments}

The authors would like to acknowledge the anonymous referees whose careful reading helped us improve this article.

\section{References}

Adamic, L.A., Zhang, J., Bakshy, E., \&Ackerman, M.S. (2008). Knowledge sharing and Yahoo! Answers: Everyone knows something. In J. Huai, R. Chen, H.W. Hon, Y. Liu, W.Y. Ma, A. Tomkins \& X. Zhang (Eds.), Proceedings of the International World Wide Web Conference (pp. 674675). New York: ACM Press.

Adler, E. (2005). Communitarian international relations: The epistemic foundations of international relations. Abington Oxon, UK: Routledge.

Agichtein, E., Castillo, C., Donato, D., Gionides, A., \& Mishne, G. (2008). Finding highquality content in social media. Proceedings of Web Search and Web Data Mining. New York: ACM Press.

Alexa, The Web Information Company. (2010). Top Sites > Reference. Retrieved February 12, 2010, from http://www.alexa.com/topsites/ category/Top/Reference

Answerbag. (2009a). About us. Retrieved January 1, 2009, from http:// www.answerbag.com/about/ Answerbag. (2009b). Trolls peeves. Retrieved January 1, 2009 from http:// www.answerbag.com/c_view/4700

Baker-Eveleth, L., Sarker, S., \& Eveleth, D.M. (2005). Formation of an online community of practice: An inductive study unearthing key elements. In R. Sprague (Ed.), Proceedings of the $38^{\text {th }}$ Hawaii International Conference on System Sciences (pp. 1-10). Washington, DC: IEEE Computer Society Press.

Berends, H., Boersma, K., \& Weggman, M. (2003). The structuration of organizational learning. Human Relations, 56(9), 1035-1056.

Bian, J., Liu,Y., Agichtein, E.,\&Zha, H. (2008). Finding the right facts in the crowd: Factoid question answering over social media. In J. Huai, R. Chen, H.W. Hon, Y. Liu, W.Y. Ma, A. Tomkins \& X. Zhang (Eds.), Proceedings of the International World Wide Web Conference (pp. 467-476). New York: ACM Press. 
Chen, W., Zeng, Q., \& Wenyin, L. (2006). A user reputation model for a userinteractive question answering system. Proceedings of the Second International Conference on Semantics, Knowledge, and Grid (p. 40). Washington, DC: IEEE Computer Society.

de Moor, A. (2006). Community memory activation with collaboration patterns. In L. Stillman \& G. Johanson (Eds.), Proceedings of the Third Prato Community Informatics Research Network Conference (CIRN 2006). Retrieved July 8 , 2010, from http://citeseerx.ist.psu.edu/viewdoc/download?doi=10.1.1.105.6343\&rep=r ep1\&type=pdf

De Souza, C.S., \& Preece, J. (2004). A framework for analyzing and understanding online communities. Interacting With Computers, 16(3), 579-610.

Dom, B., \& Paranjpe, D. (2008). A Bayesian technique for estimating the credibility of question answerers. Proceedings of the Society for Industrial and Applied Mathematics (SIAM). Retrieved January 1, 2009, from http://www.siam.org/proceedings/datamining/2008/dm08_36_Dom.pdf

Dougherty, D. (2008). Bridging social constraint and social action to design organizations for innovation. Organization Studies, 29(3), 415-434.

Evans, J., \& Brooks, L. (2005). Understanding collaboration using new technologies: A structurational perspective. Information Society, 21(3), 215-220.

Farquhar, L. (2007, May). Structuration and the online community. Paper presented at the Annual Meeting of the International Communication Association, San Francisco, CA. Retrieved June 29, 2010, from http://www.allacademic.com/meta/p168940_index.html

Gazan, R. (2006, November). Specialists and synthesists in a question answering community. Paper presented at the American Society for Information Science \& Technology Annual Meeting, Austin, TX.

Gazan, R. (2007). Seekers, sloths and social reference: Homework questions submitted to a question-answering community. New Review of Hypermedia \& Multimedia, 13(2), 239-248.

Giddens, A. (1979). Central problems in social theory: Action, structure and contradiction in social analysis. Berkeley, CA: University of California Press.

Giddens, A. (1984). The constitution of society. Berkeley, CA: University of California Press.

Giddens, A. (1989). A reply to my critics. In D. Held \& J.B. Thompson, (Eds.). Social theory of modern societies: Anthony Giddens and his critics (pp. 249-301). Cambridge, UK: Cambridge University Press.

Giddens, A. (1991). Structuration theory: Past, present and future. In C.G.A. Bryant \& D. Jary (Eds.) Giddens' theory of structuration: A critical appreciation (pp. 201-221). New York: Routledge.

Hara, N. (2008). Communities of practice: Fostering peer-to-peer learning and informal knowledge sharing in the work place. Berlin, Germany: Springer.

Hara, N., \& Hew, K. (2006).A case study of a longstanding online community of practice involving critical care and advanced practice nurses. In R. Sprague (Ed.), Proceedings of the $39^{\text {th }}$ Hawaii International Conference on 
Information Systems (p. 147a).Washington, DC: IEEE Computer Society Press.

Hara, N., Shachaf, P., \& Stoerger, S. (2009). Online communities of practice typology revisited. Journal of Information Science, 35(6), 740-757.

Hitwise. (2008). U.S. Visits to Question and Answer Websites Increased 118 Percent Year-over-Year Yahoo! Answers receives 74 percent of all U.S. visits. Retrieved November 22, 2008, from http://www.hitwise.com/presscenter/hitwiseHS2004/question-andanswer-website s.php

Jones, M.R., \& Karsten, H. (2008). Giddens' structuration theory and information systems research. MIS Quarterly, 32(1), 127-157.

Jurczyk, P., \& Agichtein, E. (2007). Discovering authorities in question answer communities by using link analysis. Proceedings of the Conference on Information and Knowledge Management (pp. 919-922). New York: ACM Press.

Kim, S., \& Oh, S. (2009). User's relevance criteria for evaluating answers in a social Q\&A site. Journal of the American Society for Information Science \& Technology, 60(4), 716-727.

Kling, R., Rosenbaum, H., \& Sawyer, S. (2005). Understanding and communicating social informatics: A framework for studying and teaching the human contexts of information and communication technologies. Medford, NJ: Information Today.

Lamb, R., \& Davidson, E. (2005). Information and communication technology challenges to scientific professional identity. The Information Society, 21(1), $1-24$.

Lave J., \& Wenger, E. (1991). Situated learning: Legitimate peripheral participation. Cambridge, United Kingdom: Cambridge University Press.

Oh, K.T., \& Lee, K.P. (2005, November). A review of frameworks for online community design with emphasis on developing online community construct. Paper presented at the International Design Congress, Taiwan, China. Retrieved February 7, 2009, http://dspace.kaist.ac.kr/ handle/10203/6737

Oh, S., Oh, J.S., \& Shah, C. (2008). The use of information sources by Internet users in answering questions. Proceedings of the $71^{\text {st }}$ Annual Meeting of the American Society for Information Science and Technology, Vol. 45 (CD-ROM). Medford, NJ: Information Today, Inc. Retrieved July 8, 2010, from http://www.unc.edu/ shoh/papers/ASIST_InfoSources_Oh_.pdf

O’Neill, N. (2007). Chacha, Yahoo!, and Amazon. Searcher, 15(4), 7-11. Orlikowski, W.J. (1992). The duality of technology: Rethinking the concept of technology in organizations. Organization Science, 3(3), 398-427

Orlikowski, W.J. (2000). Using technology and constituting structures:

A practice lens for studying technology in organizations. Organization Science, $11(4), 404-428$.

Orlikowski, W.J. (2002). Knowing in practice: Enacting a collective capability in distributed organizing. Organization Science, 13(3), 249-273.

Østerlund, C., \& Carlile, P. (2003).How practice matters: A relational view of 
knowledge sharing. In M. Huysman, E. Etienne Wenger,\& V. Wulf (Eds.), Communities and technologies (pp. 1-22). Dordrecht, the Netherlands: Kluwer.

Preece, J., \& Maloney-Krichmar, D. (2003). Online communities. In J. Jacko \&A. Sears, A. (Eds.), Handbook of human-computer interaction (pp. 596-620). Mahwah, NJ: Lawrence Erlbaum Associates.

Raban, D.R., \& Harper, M.F. (2008). Motivations for answering questions online. New Media and Innovative technologies-Industry and Society. Mevaseret Zion, Israel: Ben-Gurion University Press.

Rafaeli, S., \& Ariel, Y. (2008). Online motivational factors: Incentives for participation and contribution in Wikipedia. In A. Barak (Ed.), Psychological aspects of cyberspace: Theory, research, applications (pp. 243-267). Cambridge, United Kingdom: Cambridge University Press.

Roush, W. (2006). What's the best Q\&A site? Technology review. Retrieved January 6, 2009, from http://www.technologyreview.com/communications/17932/?a=f

Shachaf, P. (2009). The paradox of expertise: Is the Wikipedia Reference Desk as good as your library? Journal of Documentation, 65(6), 977-996.

Shachaf, P. (2010). Social reference: A unifying theory. Library \& Information Science Research, 32(1), 66-76.

Shachaf, P., \& Rosenbaum, H. (2009, February). Online social reference:

A research agenda through a STIN framework. Paper presented at the iConference, Chapel Hill, NC.

Shah, C., Oh, J.S., \& Oh, S. (2008). Exploring characteristics and effects of user participation in online social Q\&A sites. First Monday, 13, 9. Retrieved September 29, 2008, from http://firstmonday.org/htbin/cgiwrap/ bin/ojs/index.php/fm/article/viewArticle/2182/2028

Stones, R. (2005). Structuration theory. London: Palgrave MacMillan.

Warren, L. (2004). Negotiating entrepreneurial identity: Communities of practice and changing discourses. International Journal of Entrepreneurship and Innovation, 5(1), 25-35.

Wenger, E. (1998). Communities of practice: learning, meaning, and identity. Cambridge, United Kingdom: Cambridge University Press. Wenger, E. (2001). Supporting communities of practice: A survey of community-oriented technologies. Draft version 1.3, March. Self-published, Retrieved August 14, 2009 from http://www.ewenger.com

Wenger, E., McDermott, R., \& Snyder,W.M. (2002). Cultivating communities of practice: A guide to managing knowledge. Boston, MA: Harvard Business School Press.

Wikipedia. (2009). Guidelines in Wikipedia, the free encyclopedia. Retrieved January 1, 2009, from http://en.wikipedia.org/wiki/Wikipedia:Reference_ desk/Guidelines1944 